\title{
Del HORROR A LA SEDUCCIÓN. CONSUMO DE REGUETÓN EN LA CONFORMACIÓN DE IDENTIDADES MUSICALES JUVENILES
}

\author{
From Horror to Seduction. Consumption of Reggaeton in Young People's Musical Identities Composition
}

\author{
Ligia Lavielle-Pullés
}

\begin{abstract}
Resumen: La singularidad que imprime el arte de los sonidos al proceso de consumo cultural motivó el presente estudio, donde se muestra la heterogeneidad que caracteriza el consumo de reguetón, y en específico sus repercusiones en la conformación diferenciada de identidades musicales juveniles. Mediante la exploración en los significados atribuidos por los jóvenes a un género tan polemizado a la par de consumido: el reguetón, se elaboró una clasificación que expuso las distinciones asociadas a su consumo. Para ello, la ciudad de Santiago de Cuba sirvió como punto de partida, aunque los resultados de la investigación ciertamente extralimitan este espacio urbano.
\end{abstract}

Palabras clave: consumo musical, jóvenes, identidades musicales, diferenciación.

Abstract: The present study has been motivated by the singularity of the sounds art with regard to process of cultural consumption. It's explained the heterogeneity of musical consumption and specifically its repercussion about structuration of young people's identities. The research of young people's significations with respect to a polemic and consumed rhythm: reggaeton was necessary because thanks to that a classification of musical consumption is created and the same time the distinctions related with this process are exposed. Santiago de Cuba city was the initial point of this work, although the results are certainly extended to others spaces.

Keywords: musical consumption, young people, musical identities, differentiation.

Ligia Lavielle Pullés, máster en desarrollo cultural comunitario por el Centro de Estudios para el Desarrollo Integral de la Cultura de la Universidad de Oriente en Santiago de Cuba, Cuba. Investigadora en el Centro de Estudios para el Desarrollo Integral de la Cultura, de la Facultad de Ciencias Sociales, Universidad de Oriente, Cuba. Temas de especialización: sociología del arte, sociología de la música, consumos culturales. Correo electrónico: ligia_lavielle@csh.uo.edu.cu, ernesto. luperon@fco.uo.edu.cu.
Enviado a dictamen: 04 de julio de 2013. Aprobación: 25 de septiembre de 2013. Revisiones: 1. 


\section{De la obertura al intro.' A modo de introducción}

Febrero de 2012, noche de sábado, 10:00 pm, espacio público al aire libre rebosante de jóvenes donde resuena un beat fuertemente percutido, es reguetón: —iQué rico suena eso! - dice ella y levanta un brazo mientras mueve al unísono cabeza y cuerpo al ritmo de la música, en sinérgica conexión con los cientos de jóvenes que allí confluyen.

Misma fecha, diferente espacio no muy lejano del anterior, portones de una sala de concierto que despide a otros jóvenes:

- Todavía es muy temprano, vámonos para la $\mathrm{AHS}^{2}$ que va a estar bueno. Hoy es noche de rock- Dice él esperando la aprobación del resto.

— ¿Pero nada de reguetón, verdad? - interroga preocupado otro chico.

- No, gracias a Dios - concluye categóricamente otra chica.

$\mathrm{D}$ iálogos como los anteriores ponen de relieve la diferenciación producida a partir del gusto y la expresión de consumos musicales que no sólo provocan distancias simbólicas entre jóvenes cohabitantes de una misma trama urbana, sino que representan, además, la punta de un iceberg, pues tras el consumo musical de un género tan polémico -y polemizado al menos en Cuba - como el reguetón, se esconde la posible construcción de identidades juveniles.

Del mismo modo, advierten sobre un estado de opinión diverso que aún se cierne a nivel público e institucional sobre el reguetón, con posturas oscilantes entre el disgusto, la aceptación, la tolerancia y el reforzamiento de su gusto. La crítica apunta sobre todo al perfil eminentemente comercial del género y a su contenido, más cuestionado que la forma. Contrariamente, sus seguidores afirman que en esos mismos rubros criticados radica la esencia de su disfrute; actitudes desafiantes encontradas sobre todo en la juventud. En un intento de dar respuestas a tanta disparidad, las políticas culturales en manos de las instituciones asumen posturas variables: entre la permisividad de esta música en las actividades públicas que organizan —con la creación de zonas específicas para su socialización o la permisividad de su completo despliegue- y su exclusión. La primera actitud exige que las canciones escogidas no conlleven la carga moralmente degradante que posee buena parte de la producción reguetonera.

Ahora bien, la mirada de las ciencias sociales y humanísticas cubanas en torno al tema todavía no ha alcanzado la suficiente madurez, aunque ciertamente en la actualidad se vislumbra un mayor número de investigaciones que develan inquietudes teóricas y metodológicas resueltas a profundidad desde análisis interdisciplinares. Los primeros acercamientos conceptuales esbozados en los umbrales del milenio por lo general se ubicaron dentro de la musicología, la lingüística (Casanella, Rodríguez y Hernández, 2005) y someramente desde perspectivas históricosociales (Zurbano, 2006; Ziquero, 2006). En el caso de la ciencia sociológica, las incursiones comenzaron a ganar terreno después, al interior de las universidades, para intentar responder a las insatisfacciones sociales en contraste con el aumento de la popularidad del género. Sin embargo, a la perspectiva sociológica aún le falta por llenar muchos vacíos, sobre todo porque los fenómenos sociales suscitados por el reguetón son de constante mutabilidad. Bajo tales condicionantes, los investigadores cubanos que elegimos hacer sociología de la música poseemos una deuda científica, aumentada en el caso temático del consumo, cuyas aproximaciones al respecto son más escasas.

Precisamente el presente trabajo, ${ }^{3}$ en un intento por llenar tales vacíos, explora uno de los consumos musicales que sin lugar a dudas se erige como de los más cotidianos y, ipor qué no?, también impactantes, sobre todo en el sector social que escogimos: la juventud. Ello nos remite irremisiblemente a los estudios de consumo enriquecidos por disímiles aristas conceptuales y asideros teóricos. Los estudios económicos, comunicológicos, la sociología y antropología del consumo, así como las investigaciones en el campo de la filosofía y el arte, poseen miradas concomitantes del mismo proceso, pero reflejadas en la lógica de análisis 
de cada una. Aunque no pretendemos sentar clivajes más profundos entre las distintas disciplinas, y de hecho abogamos por investigaciones que alivien las alturas de los muros epistémicos entre unas y otras, sí fue necesario precisar hacia donde se encamina nuestra mirada, haciendo converger elementos de la sociología del consumo, en el marco de ese entramado científico todavía no consensuado denominado estudios culturales, y algunas aristas de la llamada sociología de la música. Nuestro estudio recorre las divergentes maneras en que los jóvenes santiagueros consumen esta música y sus correlatos identitarios, también distintivos en varias manifestaciones del proceso.

\section{De la sonata a la riquera. El consumo y su singularidad musical. Algunos apuntes teóricos}

Hace unos pocos años G. Sunkel advertía sobre "el desafío teórico y metodológico que aún suponía el tema consumo" (2006: 11), aunque sus estudios en América Latina le hubiesen encauzado prolíficamente desde varias directrices temáticas. Hoy en día, la brecha no ha sido cerrada. Es justo reconocer la presencia de muchas investigaciones empíricas destinadas a entender los entramados simbólicos relacionados con las prácticas de consumo con el fin de orientar los mercados y las instituciones culturales, así como - aunque en menor medida - de acercamientos teóricos con la finalidad de interpretar desde las ciencias el calado que ejercen tales prácticas en los actores y grupos sociales. Los trabajos en esa dirección señalan la complejidad del análisis al abordar el fenómeno desde esa triangulación, clásica e inevitable, donde se formula "económica, política y simbólica[mente]" (Sunkel, 2006: 11), la cual condiciona todavía cierta adolescencia teórica, sobre todo ante contextos demasiado dinámicos cuyos ecos poseen pues así lo requieren- disímiles lecturas.

Los marcos teóricos del tema consumo deben ajustarse a su diversidad, que estriba no sólo en la variedad y diferencia de los productos simbólicos, sino en las distancias de contextos en términos políticos y económicos. Muchas veces tales asideros no resultan suficientes en el diagnóstico, la explicación o la predicción de procesos contemporáneos que emergen de este fenómeno sociocultural, lo cual deviene en reacomodos en las bases de las teorizaciones. Así lo demuestra la interpretación del consumo musical, cuyas expresiones revelan apropiaciones asimétricas de la música. Ello exige ahondar en los significados del acto de consumir.

La construcción de la trayectoria conceptual trazada aquí se bifurca sólo en tres ejes analíticos, no con el propósito de negar otros, sino de subrayar éstos para entender mejor la singularidad del consumo musical. Ninguno de ellos resulta autosuficiente, por tanto la comunión que establecen entre sí conduce a comprender el consumo de manera abierta a la par de específica, y visualizarlo incluso, más allá de la elección -modelo de análisis más extendido-, en aquellas "no elecciones" que expresan también apropiaciones simbólicas. Para ello recurrimos a los aportes de algunos autores que teorizaron sobre el tema, pero en especial al sociólogo Javier Callejo ${ }^{4}$ y sus remisiones históricocríticas de los elementos teóricos que participan en la conformación del acto de consumir.

\section{Primer eje: consumo condicionado social y culturalmente}

Cualquier arista disciplinar sobre la que se construyan las disímiles investigaciones del tema consumo se sustenta en la idea rectora de que éste adquiere sentido en los marcos de sociedades y culturas; afirmación de necesaria mención en tanto la marca individual que evidentemente lo compone no debe oscurecer su sello social —de hecho, más pesado que el individual-, mediante el cual los grupos ritualizan, compiten entre sí, se diferencian y distinguen (Bourdieu, 1979; García Canclini, 2006).

La expansión social a gran escala del consumo musical se fortalece gracias a la acción mediática y a los soportes tecnológicos. Ello conduce a la ubicación de la música en el núcleo de redes comunicativas y socializadoras, físicas y virtuales, sobre todo juveniles. De esta manera se crean y desarrollan culturas musicales al interior de un mismo espacio nacional, que a su 
vez dialogan y se alimentan del entramado popular, tradicional o no, que constituye la cultura musical de los pueblos. De esta forma se catapulta un consumo musical donde se mezclan, en mayor o menor medida, la tradición sonora con los pujantes sonidos de la modernidad.

\section{Segundo eje: consumo organizado y regulado desde la estructura social}

La edificación escalonada de las sociedades de consumo se atisba en el horizonte del siglo XIX, cuando la industrialización inherente a los países desarrollados poseía cierto nivel de consolidación y las grandes producciones derivadas de ello constituían el motor impulsor de una emergente sociedad que comenzaba a cimentarse sobre el consumo. Con G. Simmel la sociología ubicó las primeras observaciones referidas a aquél, donde sobresale su exploración sobre los nuevos mapas de socialización urbana que reescribían las sociedades no sólo en el terreno de la economía, sino también en el de la cultura del consumo (Marinas, 2000). No sería extraño reconocer entonces la temprana inserción del consumo en la estructura social, la misma que ordena y regula las socializaciones establecidas a partir de él. De ello dan cuenta muchas encuestas e investigaciones sobre el tema, que inician en este tópico explícita o implícitamente. Una de las expresiones de su ordenamiento macro-estructural es la de los espacios de socialización físicos o virtuales.

En este punto es necesario traer a colación, a modo de ejemplo, una sucinta referencia a cómo la estructura social cubana -manifiesta en este caso en los espacios de sociabilidad - organiza y condiciona los consumos musicales que aquí explicitamos. Pensemos por un momento en algún minúsculo espacio intersticial o institucionalizado, no legitimado para el desarrollo musical — digamos el transporte público, cualquier área de la red de mercados, una escuela, edificación habitacional, la calle, etcétera- donde necesariamente confluyen y hasta colisionan sujetos de las más distintas generaciones, estratos y grupos sociales. La pluralidad de gustos y músicas va permeando el universo simbólico de quienes constantemente se encuentran bajo la influencia sonora. En la orilla opuesta, otros espacios de socialización legitimados musicalmente pueden dirimir y a su vez diferenciar a los actores que eligen ser el público de sus ofertas. En ambos casos, los actores están bajo la influencia directa o indirecta de consumos musicales condicionados por espacios de sociabilidad, criterio que nos hace plantearnos una interrogante medular: ¿qué se entendería entonces por la acción de consumir?

\section{Tercer eje: consumo como uso y apropiación}

En la última década del siglo XX, Néstor García Canclini definía el consumo como "conjunto de procesos socioculturales en que se realiza la apropiación y uso de productos" (2006: 80). Su adaptación conceptual a los más disímiles materiales simbólicos provistos de valor cultural resultó de mucha utilidad para los autores que aportan al tema. No obstante, en el marco de un siglo XXI mundialmente tecnocrático, de sociedades estructuradas con base en el consumo, conviene revisitar cada uno de sus presupuestos y ajustarlos cuando se requiera, esto es, cuando la realidad desafíe la noción abstracta del proceso. De ahí se impone pensar el consumo —incluido el consumo musicaldesde los dos procesos intrínsecos que lo definen: uso y apropiación.

Las pistas de estas dimensiones nos retrotraen al mismo Karl Marx quien, aunque no basó su obra en el consumo, sí lo nominó como la objetivación del valor de uso (1981: 1), al tiempo que dejaba una brecha —en ese acápite sobre le fetichización de la mercancía- donde ya se reflectaban las cualidades simbólicas del proceso. Aunque otros autores también se refirieron al uso, como por ejemplo Weber y M. de Certeau, la óptica de Marx resulta sustancial para la explicación del proceso que nos ocupa.

En ese sentido coincidimos con el análisis de Callejo no sólo al definir grosso modo el uso como la relación/ acción que ejercen los sujetos sobre los objetos de consumo, sino al detenerse e interpretar el aporte marxista, que supone a su vez aludir a la apropiación. 
"El uso va más allá del acto de compraventa para alojarse en el ámbito de la apropiación (subjetivación de lo objetivado) del objeto por parte del agente [...] Apropiación por la que el usuario incorpora lo usado, y de alguna manera transforma al propio objeto" (Callejo, 1995a: 80). A través de Marx, y posteriormente de otros teóricos como este sociólogo español, podemos pensar el acto del consumo en términos de usos expresados en apropiaciones, lo cual significa internalizar lo usado; no sólo poner en práctica su utilidad, sino aprehender simbólicamente el producto consumido. Ahora bien, ¿cómo se traducirían tales presupuestos a la música?

A diferencia de las demás artes, la música posee como materia prima básica el sonido y su traslado espacial se ejecuta con independencia de la voluntad de quienes lo oyen e incluso de quienes lo escuchan. Por ello, el consumo musical difiere del que acontece en otras artes y producciones de la industria cultural como el cine, la literatura o la pintura. La disposición para leer un libro o para asistir a la sala cinematográfica o a la galería marca un consumo, condicionado gracias al gusto por determinada película u obras/autores de artes visuales y literarias. Sin embargo, el actor social no debe disponer necesariamente su gusto para incorporar la música a su universo simbólico. Por eso, su consumo resulta más cercano, por ejemplo, al de la publicidad, "cuyos mensajes actúan entre la sugerencia y la imposición” (Callejo, 1995b: 83).

Ello condiciona un uso y apropiación musicales que describen un arco de prácticas — diferenciadas-, desde la elección de la música, la adquisición del disco, el baile, canto y disfrute, hasta una apropiación menor -influenciada por la saturación sonora de melodíasexternalizada en la escucha, el simple marcaje rítmico, el reconocimiento de los cantantes y exponentes visuales de los géneros musicales y la interpretación de sus significados. Las prácticas mencionadas a manera de ejemplo suponen a su vez una toma de partido a favor, muy a favor o en contra de determinada música, pero ya se inscriben en el ancho espectro del consumo musical que puede conceptualizarse como procesos de uso y apropiación condicionados socio-culturalmente que suponen la incorporación de los significados implícitos de la música oída o escuchada, ya sean sus aspectos formales - esquemas armónicos, melodías y ritmoso de contenido - la letra de la canción- Asimismo, y siguiendo las pistas de García Canclini respecto al consumo cultural, los productos donde nace este proceso poseen un valor simbólico superior a los de uso y de cambio.

Se colige de ese modo una visión amplia a la par que heterogénea del consumo musical, lo cual permite su comprensión a través de clasificaciones. La diferenciación que opera en los actores sociales consumidores - jóvenes en este caso particular- no estriba precisamente en el hecho de consumir reguetón-, sino en las maneras asimétricas de hacerlo. Los procesos de apropiación que lo definen se relacionan además con otras manifestaciones aglutinadas a su alrededor, como el videoclip o el baile que caracteriza a un género específico. También explicitan la conexión binaria mercado y música.

Todo ello forma parte del objeto de estudio de la sociología de la música, disciplina que ha prestado atención a los estudios sobre consumos musicales. Sin embargo, en ella se evidencian todavía amplios vacíos teóricos así como confusión, dada en la aparente similitud de gustos y consumos, implícitos en investigaciones donde se mencionan indistintamente.

\section{Del scherzo a la masacre musical. Consumo musical en el marco de la conformación de identidades}

El maridaje temático entre consumo cultural e identidad(es) se manifiesta hoy como uno de los nexos privilegiados en los discursos académicos de aquellos que indagan en las problemáticas de las sociedades del presente, sobre todo en el plano de la cultura. Las investigaciones en este sentido se bifurcan en varias tendencias: una pondera el consumo en el espacio urbano como contexto condicionante en la formación de identidades (García Canclini, 1995; Guzmán, 2008); otra enfatiza en las culturas juveniles, donde es fácil ubicar el proceso de consumo subsumido en la formación de estilos nucleados mediante identidades colectivas (Feixa, 1999; Urteaga, 1998; Marcial, 2009), y una tercera 
fusiona ambas (Pallarés, Costa y Feixa, 2002; Bermúdez, 2008). Y es que a partir de este acto de apropiación los actores pueden tanto diferenciarse unos de otros, como identificarse y reconocerse en el grueso tejido social, formando comunidades que pueden poblar espacios globales, virtuales y transnacionalizados.

La actuación de la industria fonográfica condiciona la emergencia de comunidades consumidoras, agrupadas por el autorreconocimiento identitario y gravitando alrededor de la preferencia por un determinado género y producto cultural-musical. Los jóvenes históricamente han sido los protagonistas de estos fenómenos provenientes del gusto y el consumo colectivos. La construcción identitaria instituida en jóvenes y adolescentes sobre la base de nociones nacionales o territoriales sigue sustituyéndose ${ }^{5}$ por la que se conforma a través de los gustos y consumos musicales.

En la actualidad más que nunca, la organización de tales comunidades excede la presencia física, toda vez que el desarrollo tecnológico ha dado el espaldarazo necesario para la formación de redes comunicativas y de consumo. Se evidencia entonces la conjunción consumo musical e identidades juveniles, tema investigado prolíficamente desde los estudios de culturas juveniles. ${ }^{6}$ Este campo interdisciplinar ha sido bordado históricamente a partir de las explicaciones en torno a la formación de colectividades juveniles —denominadas históricamente subculturas, contraculturas, tribus, grupos, colectivos - nucleadas desde identidades colectivas, en un intento de marcar territorios delimitados que hagan frente en mayor o menor medida al adultocentrismo dominante que resguarda en su interior relaciones de poder. Pertinente resulta entonces colocar un dedo enfático sobre una de las aristas que aseguran la pertenencia a grupos o colectividades juveniles, la musical.

Por lo general, los estudios de culturas juveniles y sus consumos discursan sobre "identidades juveniles" y no sobre "identidades musicales juveniles", en tanto la música es sólo una hebra más de esa urdimbre cultural en construcción. Sin embargo, merece la pena pensarla como factor aglutinante, pues abundan los ejemplos en que puede observarse su preeminencia sobre las demás expresiones culturales, como las estéticas y discursivas, superpuestas en buena medida a la constitución del producto musical.

Con este pretexto, y partiendo desde un punto de vista micro que apunta a reordenarse de manera macro, creemos que las identidades musicales - juvenilesconstituyen una dimensión más de la identidad, que define al sujeto como individuo singular, la cual se configura a partir de la posición o actitud que asume el actor social —el joven en este caso - respecto a algún género musical —devenido o no en producto cultural-, bien sea la preferencia o el disgusto, incorporados a la conciencia de mismidad ${ }^{7}$ que le define. Le permite autorreconocerse, distinguirse y relacionarse a través de un intercambio simbólico con los demás, hasta llegar a constituir identidades colectivas. Su conformación alrededor del gusto marcado por algún producto musical y su consecuente consumo indiscriminado derivan en que el joven asuma elementos provenientes de aquél y lo exteriorice en discursos y estéticas que le aportan a su sentido de unicidad y a la vez colectividad.

Estas identidades musicales - juvenilesestablecidas a nivel micro se expresan entonces en la preferencia marcada por un género determinado o en el rechazo a otro; en la asunción intensa o sinuosa de prácticas derivadas de la música, por ejemplo el cantar o el bailar, así como en la asistencia electiva a espacios musicales de socialización.

A partir de los consumos musicales con que nos interpela la realidad santiaguera y de los sustentos teóricos hasta aquí esbozados, elaboramos una clasificación que explicita cuatro modos de consumir música, en relación con la intensidad del proceso y en función de las identidades musicales juveniles que se construyen con referencia al reguetón.

\section{De la suite a El animal. Pautas metodológicas en el estudio del consumo musical}

"La música es un hecho social" (Silbermann, 1960). Ésta constituyó la idea implícita en todo el estudio y permitió el desplazamiento de las coordenadas conceptuales del consumo cultural hacia la médula 
analítica de la investigación: el consumo musical, variable analizada. La conformación del marco teórico se anudó con la construcción del dato empírico orientado en el uso combinado de la metodología cuantitativa y la cualitativa, con preponderancia de la segunda, pues analizar las diferentes maneras en que se expresa el consumo de reguetón exigió ver más allá de cuántos jóvenes lo consumen y qué significados le otorgan.

El género que referimos muta constantemente debido a la lógica comercial con la que se crea, de ahí que muchos resultados encontrados durante el trabajo empírico corresponden a un período específico. Este estudio se realizó entre 2010 y la segunda mitad de 2012, y la recogida de información ${ }^{8}$ se centró entre la primera mitad de 2010 y la segunda de 2011. Hoy en día, bajo el contexto del más inmediato 2013, se perciben variaciones, ${ }^{9}$ por lo que insistimos en señalar el lapso durante el cual el presente trabajo tomó cuerpo.

El rango etario que se tuvo en cuenta abarcó entre los catorce y los veintinueve años, pues constituye el rango etario demográficamente contemplado por la Oficina de Estadística Nacional para estudiar este sector social. El universo refirió a los jóvenes santiagueros; y la muestra o unidad de análisis, a 75 jóvenes.

Comprender el modo en que los jóvenes pensaban, sentían y se expresaban en función del reguetón sustentó la utilización de la observación científica como método empírico, así como de técnicas de corte etnográfico. Escogimos tres comunidades al azar, ubicadas al interior y exterior de los límites del centro urbano, y relativamente lejanas entre sí, donde realizamos treinta entrevistas abiertas semiestructuradas a jóvenes de ambos sexos.

Al mismo tiempo hicimos uso de la observación en varios recorridos sistemáticos por la ciudad que nos permitieron un paneo de los principales espacios de socialización musicales donde el reguetón ganaba protagonismo. Una vez reconocidos, y a través de la observación participante, procedimos a la caracterización de sus dinámicas socio-musicales. Con esta misma técnica interactuamos con diversos jóvenes en muchas de sus actividades frecuentes, festivas o no. Desde allí reconocimos el uso o desuso de elementos estéticos y orales popularizados a partir del reguetón. Al cruzar los datos construidos mediante ambas técnicas, nos percatamos de insoslayables coincidencias. Posteriormente, encuestamos a treinta jóvenes de otras tres comunidades también distantes entre sí; en dos de ellas realizamos dos grupos de discusión con un total de quince jóvenes. En la realización de estas técnicas procuramos siempre que fue posible contar con actores de ambos sexos, diferentes estratos sociales, estudiantes, trabajadores, o no estudiantes ni trabajadores.

Entrevistamos en profundidad a dos jóvenes creadores de reguetón - no músicos- y contamos con las opiniones de dos intelectuales de la música. También analizamos la imagen audiovisual obtenida a partir de los videoclips de reguetón, no tras la finalidad de indagar en el videoclip en sí mismo como producto estético, sino como otra manera de entender los direccionamientos comerciales del género.

La clasificación propuesta exigió instrumentar tres criterios con la finalidad de explicar cada uno de sus eslabones, subrayando su dimensión diferenciante. Su génesis analítica provino de los marcos conceptuales del estilo, enarbolados por los estudios de culturas juveniles, y adaptados al caso particular de nuestro objeto de estudio.

Entendemos junto a Feixa que el estilo ${ }^{10}$ puede definirse como "la manifestación simbólica de las culturas juveniles, expresada en un conjunto más o menos coherente de elementos materiales e inmateriales, que los jóvenes consideran representativos de su identidad como grupo" (Feixa, 1999: 97) o "la combinación jerarquizada de elementos culturales (textos, artefactos, rituales)" (Feixa, 1999: 100), al tiempo que destaca y explica entre sus principales componentes el lenguaje, la música, la estética, las producciones culturales y las actividades focales.

Las distancias entre los estilos y, de manera más global, entre las propias culturas juveniles, se estrechan en la permanencia de cuatro rasgos bastante generalizados a los cuales aluden varios estudiosos de este campo interdisciplinar: "el lenguaje o la jerga, la música, la estética y las producciones culturales" (Urteaga, 1998: 56). 
Las condicionantes sociales del consumo musical del reguetón, especialmente su explosiva expansión por toda la trama urbana, sustentaron la adaptación de los vértices fundamentales de la noción de estilo, con el fin de ser instrumentados en criterios que permitieran su caracterización diferencial en los jóvenes santiagueros. De ese modo los sustituimos por tres coordenadas analíticas:

Preferencias musicales: sintetiza "la música" y "las producciones culturales" esgrimidas por la noción de estilo y permite aludir a la vivencia del arte de los sonidos. Se objetiva en el gusto y sirve como referencia para el disfrute o disgusto de los sonidos armonizados, como respuestas a un proceso de consumo musical. En este criterio se incorporan los espacios musicales de socialización, señalizadores de qué lugares escogen los jóvenes para desplazarse en relación con sus preferencias. Allí se incluyen además "las actividades focales", que sobresalen entre los elementos del estilo y que se traducen en este caso en la propia estructuración del gusto de los jóvenes que consumen de manera intensa el reguetón. ¿Qué tanto visualizan los jóvenes a sus cantantes a través de videos o publicaciones, qué tan informados están de los aconteceres en torno a ellos y al mismo género, por qué escogen unos espacios socializadores en vez de otros, cómo se suscriben o se alejan del circuito musical "underground"ll $u$ oficialista a manera de red? Las respuestas a estas interrogantes colocan en la mira las diferencias alrededor de las distintas preferencias en cada joven respecto al reguetón.

Los elementos estéticos: aluden a la incorporación o no de la estética que caracteriza al producto musical, como contraparte de las ideas y basamentos textuales que catapultan al género. Sustituyen en ese sentido a la "facha" de los estudios de culturas juveniles y que refieren lo mismo.

Las oralidades secundarias: el lenguaje o la jerga, como también se le ha conocido, los intercambiamos por aquella expresión acuñada por E. Monsonyi, oralidades secundarias: "Viene dada por la acción de los grandes medios de comunicación, cuando no por la influencia retroactiva de la escritura sobre el desempeño oral. De esta manera la radio, el cine y la televisión [a los que sumamos bajo la misma lógica enumerativa la música, el videoclip y las redes sociales] nos abruman con un tipo de oralidad difícil de imaginar en siglos anteriores: una forma de comunicación del lenguaje articulado que supone la presencia interesada de vastos auditorios pendientes de este tipo de comunicación unidireccional" (Monsonyi, 1990: 6).

El concepto describe coordenadas coincidentes con la realidad del lenguaje oral, musicalmente popularizado por la huella del reguetón y extendido a todo el universo juvenil dada la acción de los medios comunicativos y sobre todo por los usos de las tecnologías. En esa perspectiva resulta más certero aludir a él que a la jerga, pues el primero logra mayor expansión simbólica; así, como apuntaremos más adelante, no todos lo usan pero casi todos lo reconocen en mayor o menor medida.

En la definición de la jerga se detalla su conformación en oposición al mundo adultocéntrico y su creación mediante préstamos de elementos de sociolectos de argots marginales, pero en el caso que nos ocupa la fraseología no se opone al mundo adulto - lo cual no limita su mayor repliegue entre los jóvenes-, de hecho se teje justo al interior de los argots marginales. Por otro lado, a veces los argots juveniles de grupos específicos - skin, mods - alcanzan amplias capas poblacionales según se expone en los conceptos de jerga; sin embargo, la fraseología del reguetón casi siempre se difunde a gran escala a través de la popularización de las canciones de tal manera que se difuminan quienes lo crean, sin contar que sus mayores consumidores no llegan a conformar un grupo.

Resulta muy discutible, no obstante, el carácter unidireccional de la definición de oralidades secundarias. Incluso en el análisis de E. Monsonyi, el receptor o consumidor posee un papel pasivo, perspectiva que, aunque minó por mucho tiempo los estudios de recepción y audiencia, fue marginada también hace unas décadas por sus teóricos, cuyos aportes compusieron algunos de los sedimentos inherentes a las teorías de 
consumo. Siendo coherentes con esta crítica, pero también con la realidad santiaguera y cubana que permea la construcción del dato empírico y nuestro aporte, optamos por el concepto de oralidad secundaria al tiempo que enfatizamos el carácter cocreador de los consumidores juveniles, muchos de los cuales intervienen de maneras muy activas en el proceso de creación, producción y distribución del reguetón. Oralidades secundarias por la gran extensión social y simbólica que ocupa entre los jóvenes y su importancia en la interacción juvenil, pero con un marcado carácter pluridireccional.

\section{Si todo el mundo sabe que yo soy "el animal". Paneo sociocultural sobre el reguetón en Cuba}

En este apartado esbozamos grosso modo la introducción del género en la isla de Cuba, especialmente en Santiago, algunas de las características que han pertrechado su permanencia y los espacios de socialización musicales donde su inserción es prácticamente inmanente. Con ello pretendemos aludir de manera general al contexto musical en el que se ha desenvuelto el fenómeno estudiado en virtud de su mejor comprensión.

Todavía no existe una opinión consensuada sobre sus orígenes geográficos, oscilantes entre Panamá y Puerto Rico. En contraste, su procedencia social no deja espacio para las dudas; los barrios periféricos de las ciudades del Caribe. El surgimiento del reguetón invocó la inmediata atención del mercado musical, donde comenzó a ser aprovechado y catapultado por algunas casas disqueras que vieron minas abiertas en su alcance comercial.

Por su parte, su introducción en Cuba se produjo al unísono con su trayectoria creativa desde las postrimerías de los ochenta, cuando todavía se hablaba de dance hall y reggae en español, vertientes de su génesis musical. Las creaciones cubanas, sin embargo, debutarían a finales de los noventa.

Desde ese entonces, los mecanismos de creación y distribución en el contexto cubano se desenvolvieron por rumbos divergentes a las disqueras pertenecientes a la industria fonográfica cubana legitimada por las políticas culturales estatales, lo que condicionó una circulación mayormente de modo underground o subterráneo, tanto el de factura internacional como el nacional. Actualmente, ésa sigue representando su vía principal de circulación amén de las coberturas mediáticas. Desde esa época hasta el momento actual, su fuente principal de creación se gestó en los estudios domésticos de las denominadas "productoras particulares", de espaldas a las disqueras estatales. A estos estudios también se les denomina "emergentes" y han ganado tanto en reconocimiento público, como en críticas alusivas a su labor.

La peculiar "protoindustria" disquera doméstica todavía modesta en términos de estructura comercial y de gestión cultural, que no representa en absoluto sinónimo de poca o mucha calidad - sita en más de un hogar posibilita que los jóvenes posean el producto más cerca, incluso desde el mismo momento de su creación, cuando el cantante - que por lo general también es joven - toma inspiración de experiencias cotidianas. Por otro lado, los jóvenes regularmente son los principales protagonistas de su circulación. De este modo se convierten en cocreadores del reguetón o, con más razón al decir de De Certeau, en "productores secundarios".

Estos estudios domésticos representan una de las fuentes principales que nutren los espacios de socialización donde el género, en Santiago de Cuba, gana protagonismo. Resulta común para el transeúnte en su recorrido por la trama urbana santiaguera y en general cubana, hallar a su paso - 0 quizá sería mejor referir a su escucha- los sonidos intensamente percutidos del reguetón, pero si de festividades locales se trata, los impactos son más frecuentes. Por eso señalizamos algunos, en función de una breve caracterización en la que se hace común su permanencia musical. Con tales prerrogativas los dividimos en dos tipologías.

1. Espacios musicales de socialización públicos donde el reguetón gana protagonismo:

- Fiestas comunitarias informales, sin direccionamientos institucionales. Se producen 
tanto en espacios públicos comunitarios barriadas - bajo el pretexto de festividades nacionales, locales, comunitarias o familiares. También se producen en la parte frontal de las viviendas - portales o corredores- o en edificaciones multifamiliares.

- Espacios abiertos o cerrados con entrada de pago, con direccionamientos institucionales. Se ubican aquí, por citar algún ejemplo, cabarets como el conocido "Tropicana" y sitios también de recreación: "La Claqueta" o "Son América".

- Espacios abiertos de entrada libre: son zonas específicas del ancho tramo donde transcurren las denominadas "noches santiagueras", por ejemplo el espacio conocido como "Plaza Juvenil".

2. Espacios musicales de socialización públicos donde se incluye relativamente el reguetón. Espacios cerrados con entrada de pago y velados institucionalmente con su ejemplo más representativo: la Casa de la Música. Estos espacios y las asociaciones negativas o positivas que sobre ellos ciñen los santiagueros, jóvenes o no, coadyuvan a la conformación de mapas simbólicos urbanos en cuyos trazados la música posee un papel significativo. Otros aspectos pudieran abordarse sobre los contextos que tipifican los consumos del género en Cuba y en Santiago, pero de una manera u otra se reflejan en el terreno de la diferenciación que exponemos a continuación.

De la Sinfonía inconclusa al A mí me gusta la gasolina. Clasificación por niveles del consumo musical de reguetón en la conformación de identidades musicales juveniles

\section{Primer nivel. Consumo musical involuntario e identidades musicales opuestas al reguetón}

Este nivel lo integraron los jóvenes que expresaron con énfasis que no les gustaba el reguetón. Algunos opinaron sentirse agredidos por él debido a la constante saturación sonora que imponía, así como por su letra y música. Aquí confluyó un 8\% del total con que trabajamos, lo que representa a seis jóvenes.

Preferencias musicales: afirmaron que no les gustaba nada el reguetón; de hecho, a algunos les disgustaba sobremanera. Aquí se escucharon frases como la siguiente: "idonde quiera que uno va se encuentra con esa música que atormenta! $\mathrm{O}$ incluso si te vas a comer un bocadito o una pizza, ahí está el reguetón".

De ahí la explicación de que su escucha está condicionada por la constante saturación e imposición musical, pues resulta difícil escaparse a esos sonidos que a todo volumen se encuentran diseminados en diversos espacios de la trama urbana. Se impuso entonces la lógica pregunta: si pareciera que a estos jóvenes no les gustaba el reguetón -e incluso algunos expresan su notable desprecio por él一, ipodrían considerarse consumidores musicales?

La respuesta fue afirmativa, pues desde el momento en que más allá de oírlo, lo escuchaban, interpretaban - ya sea sólo para ejercer la más dura crítica- y reconocían en alguna medida a sus exponentes, se producía la apropiación de elementos intrínsecos del reguetón, la subjetivación del sonido y sus significados. En ocasiones, algunos se sorprendían al verse reproduciendo mediante "tarareos" algún estribillo melódico de aquel género que repelían. Este consumo escapaba a la voluntad de tales jóvenes y puede valorarse de carácter mínimo, cognoscitivo, pero al fin y al cabo ha resultado consumo musical. Afirmaron que si pudieran elegir a qué espacio desplazarse para la recreación, no privilegiarían aquellos donde el reguetón ganaba protagonismo y que referimos anteriormente. No es casual, por tanto, que ubicaran en sus primeros escaños de preferencias teatros y salas de conciertos, sin soslayar otros cuyas propuestas fueron variadas, incluso bailables, pero donde el reguetón quedaba desplazado.

Elementos estéticos: "No me gusta cómo se visten por lo general, tanta ropa escandalosa, con tanto brillo encima, qué mal gusto". Con frases como ésta ejemplificaron su no preferencia por el uso de prendas y accesorios típicos extendidos como moda por los cantantes de reguetón. Todos reconocieron muchos 
de sus elementos estéticos característicos, pero la mayoría se inclinó a marginarlos dentro de sus gustos personales, e incluso algunos lo denominaron "ropa escandalosa", "de mal gusto".

Aun así, la moda constituye un fenómeno en constante expansión y, por ende, este gusto condicionado por factores económicos, históricos, sociales y culturales no debería verse desde una postura inflexible. Las mismas estéticas de los cantantes de reguetón actúan como señalizadores del mercado, de ahí su dinámica transformación. Por ello, más que al hecho objetivo señalado por los jóvenes en cuanto a "yo no uso esa ropa”, es coherente aludir a su disposición negativa en relación con su uso. En ese sentido valoramos no tanto lo que usan, como lo que están dispuestos a usar.

Oralidad secundaria: La mayoría de los jóvenes reconocieron la extensión social del uso de frases y palabras muy recurrentes en las canciones de reguetón, pues formaban parte de su cotidianeidad y de la sociabilidad instituida entre unos y otros. No obstante, los incluidos en este nivel también coincidieron en que incorporaban esas expresiones poco a sus discursos frecuentes, incluso en situaciones informales. Ello no quería decir que la comunicación se obstruyera, pues en mayor o menor medida reconocían los significados implícitos en ellas. No podría ser de otra manera; en el universo juvenil que les rodeaba, la fraseología popularizada por el reguetón había permeado la comunicación de tal manera que se hacía inevitable reconocer al menos una buena parte del flujo de sus significados, aunque es justo señalar que para ellos no era frecuente su uso.

\section{Segundo nivel. Consumo musical ocasional e identidades musicales semiestructuradas respecto al reguetón}

En este nivel se ubican los que expresaron que no les gustaba el reguetón pero, del mismo modo, no lo excluían completamente de sus listas si de ocio se trataba. Dicha dualidad condicionaba mayores inserciones juveniles, expresadas en la superioridad numérica respecto al anterior. Aquí confluyeron veintiún jóvenes, lo cual representó un 28\% del total.
Preferencias musicales: la mayoría planteó que no le gustaba, mientras otros argumentaron que, aunque les gustaba un poco, no lo privilegiaban en su espectro musical. La coincidencia unificadora de sus criterios sobresalió cuando afirmaron que lo bailaban y lo disfrutaban circunstancialmente durante fiestas y cualquier otra ocasión festiva o alusiva a la diversión. Más de una explicación se encontró en el núcleo de esta dualidad del consumo musical expresada en criterios como éste: "No me gusta el reguetón, es muy ordinario, pero sí lo bailo cuando está el ambiente".

Por un lado, sería injusto desconocer la misma génesis músico-cultural del género que lo sitúa en el Caribe, mosaico cultural cuya expresión en sus ritmos típicos -entre los cuales emergió éste en específicoforma parte de la identidad cultural cubana, vista así a nivel macro. De ahí que en opinión de muchos jóvenes el reguetón se catalogue como "pegajoso", ${ }^{12}$ lo cual induce con mayor facilidad a un baile de movimientos libres, ${ }^{13}$ aspecto también identitario de una buena parte de los bailes caribeños donde se evidencia, a pesar de la distancia temporal y ya cultural, la huella de África.

En cuanto a los espacios musicales de socialización, en este nivel todavía resulta notable cómo sobresalieron aquellos donde el reguetón no ganaba protagonismo. Así, los que más se repitieron fueron salas de conciertos y espacios teatrales, aunque ya comenzaba a incluirse de manera más marcada la asistencia a aquellos donde la variedad musical abría paso a este género; dígase, por ejemplo, algunos de espacios cerrados, como la Casa de la Música. Ello evidencia variaciones diferenciantes con respecto al nivel anterior.

Elementos estéticos: por lo general estos jóvenes los incorporaron escasamente, pero los reconocieron de manera global. La tendencia más marcada apuntó a su desuso personal, donde coincidieron con los anteriores.

Oralidad secundaria: reconocieron también una fraseología inherente al reguetón expandida en el discurso popular actual; sin embargo, a diferencia de los anteriores, comenzó a elevarse la propensión a utilizarla en su propio vocabulario cotidiano. ${ }^{14}$ 


\section{Tercer nivel. Consumo musical aceptado e identidades} musicales intermedias respecto al reguetón

Tácitamente reconocieron que les gustaba el reguetón y lo privilegiaron como uno más entre los géneros musicales que preferían, aunque por lo regular no asumían a plenitud todos sus parámetros, hecho que convirtió en intermedia esta particular forma de consumo. Aquí coincidieron diez jóvenes, lo cual representó un 13.3\% del total trabajado.

Preferencias musicales: los jóvenes expresaron su preferencia electiva por la música reguetón entre la diversidad de géneros que escuchaban. Generalmente, no sólo lo seleccionaban, sino que lo cantaban, bailaban y disfrutaban a plenitud bajo circunstancias festivas o no, reconocían a sus cantantes y podían discernir cuáles estaban de moda. En este sentido, se mostraron más cercanos a la segunda clasificación que a la primera. Por lo regular, y coherentemente con sus gustos, seleccionaron espacios musicales de socialización diversos, donde emergieron constante y privilegiadamente aquellos que otorgaban protagonismo al reguetón.

Elementos estéticos: muchos de ellos coincidieron en reconocer - de manera más explícita que los anteriores - la peculiar imagen de los cantantes del género, dejando ver que conocían los elementos culturales construidos a partir de éste. Sin embargo, en relación con su uso no se sintieron totalmente cómodos, y de usarlos sólo lo hacían circunstancialmente. Ello señalaba una apropiación estética que todavía se resistía a ser reflejo de este producto musical.

Una de las observaciones importantes residió en que los elementos estéticos característicos del reguetón eran pensados básicamente para sus principales exponentes, masculinos, casi en su totalidad. Las mujeres cantantes de reguetón eran realmente pocas, tanto en su cuna - Puerto Rico y Panamá - como en el caso cubano.

En cuanto al tema de la estética femenina, dentro del reguetón cubano reconocimos dos tendencias en su discurso audiovisual que condicionaban su uso. Una de ellas explicitaba en mayor o menor medida la sexualidad de la mujer desde una óptica machista. Se perdía el poder artístico de la sugerencia, donde reside el buen tratamiento audiovisual de lo erótico, para mostrar palmariamente partes corporales femeninas: senos, glúteos e incluso desnudos pornográficos. Esta tendencia es la que caracteriza por lo general a las jóvenes que participan como bailarinas en los videos. La otra visualizaba la incorporación de elementos masculinos a una desbordante sensualidad, a veces también machista, conformando así una imagen híbrida. En esta tendencia se incluyeron por lo general las cantantes del género. ${ }^{15}$

Dada la complejidad que supone este hecho estético, las jóvenes asumieron ocasionalmente algunos elementos de la segunda tendencia, sobre todo los que no poseían carga machista. Destacó en este caso lo que se ha dado en llamar en Cuba moda mickie, ${ }^{16} \mathrm{e}$ incluso se evidenció la transposición de modos masculinos de llevar el cabello; por ejemplo, se hablaba del peinado masculino conocido en Cuba como yonky, ${ }^{17}$ adaptado al uso femenino.

Oralidad secundaria: como tendencia regular, los que integraron este nivel también reconocieron que, a partir del reguetón, se extendió una fraseología que se colocó en el discurso cotidiano pero, al igual que en el apartado anterior, no se sentían muy cómodos usándola y, de ser así, lo hacían en pocas ocasiones.

\section{Cuarto nivel. Consumo musical marcado e identidades} musicales estructuradas respecto al reguetón. Reguetoneros

La preferencia marcada por el reguetón y la asunción paralela de los elementos que de él se derivan constituyeron los factores que permiten hablar de un cuarto nivel de consumo musical. Si se vuelve la vista atrás, resaltaron las diferencias en cómo se produjo su apropiación. Aquí coincidió prácticamente la mitad de los jóvenes a quienes se les aplicaron los instrumentos de investigación.

Preferencias musicales: “-iTe gusta el reguetón?, -Pues claro. ¿A quién no le gusta el reguetón?" Así comenzaron muchas de las entrevistas a jóvenes santiagueros. La obviedad de las respuestas indica que otras no eran posibles. Afirmaron generalmente que lo bailaban porque el ritmo era "pegajoso, que 
no va a morir por ahora" $y$, aunque se ha expandido por doquier, seguía representando la parte "periférica baja", o sencillamente "al gueto" de la ciudad, por eso también les gustaba. Ello permite pensar que todavía se construyen imaginarios colectivos respecto a un producto musical que hace tiempo sobrepasó las fronteras de las primeras voces y oídos.

Los jóvenes que conformaron este nivel sí conocían con certeza hasta la última canción de moda del reguetón y, más que escucharlo, lo vivían prestando atención a sus constantes movimientos internos, en virtud de los que construyeron una parte esencial de sus experiencias musicales sobre la base del consumo. Por eso, estar informado sobre el último tema que sonaba en "la calle", conocer su presencia en diferentes escenarios cubanos, los últimos acontecimientos que los involucraban o qué nuevo cantante emergía de una multitud con la cual competía, fueron actitudes $y$ actividades frecuentes que subrayaron la vivencia cultural de estos actores sociales en torno al reguetón.

Los espacios musicales de socialización más sobresalientes fueron en general las dos tipologías mencionadas con anterioridad, mientras, paralelamente, fue en disminución el gusto por salas de concierto o espacios teatrales.

Elementos estéticos: "-Eso es lo que se lleva, lo que se usa, claro que quiero estar a la moda”. La imagen que caracteriza al cantante de reguetón ha variado con el paso de los años. Recordemos su nacimiento embrionario apegado al rap, condicionante de estéticas bastante similares en los inicios del género. La imagen enarbolada por el rap era coherente con un discurso de protesta que permeó al reguetón en alguna medida en sus primeros pasos. La visualidad irreverente del rap, conocida como "repa" - de los vocablos repartero y reparto - pretendió impactar no sólo desde el sonido, sino también desde lo visual: pantalones anchos, muchas prendas de oro, pulóveres anchos, gorras ladeadas. Su asunción por los exponentes del reguetón varió de la misma manera que se transformó su discurso en la consabida díada de la canción: música y letra. Aunque este proceso acaeció lentamente - sobre todo en el plano cubano-, fue coherente con el mensaje generalmente lúdico y descomprometido del género. De esta manera se sustituyó la estética repa por la mickie, consistente en prendas apretadas de explícito contenido erótico: pantalones ceñidos, denominados popularmente "europeos", pulóveres brillantes y de colores intensos, cadenas gruesas, gorras, lentes oscuros - gafas - llamativos y modos singulares de llevar el cabello. Por parte de los jóvenes que en este nivel confluyeron, la asunción de la estética señalaba una manera de vivirlo e identificarse con él, no sólo de manera objetiva, sino también como pretensión. ${ }^{18}$

Es importante señalar aquí que lo "repa", como concepto, no es un elemento totalmente desfasado en el reguetón; sólo la estética ha sido sustituida, pero continúa impactando desde el contenido, sobre todo verbal, de las canciones.

Por otro lado, se advierte que la mayor parte de los jóvenes que constituyeron la muestra fue del sexo masculino. Este hecho no es fortuito. La vivencia del reguetón y la asunción coherente de sus rasgos estéticos se efectuaron de manera menos contradictoria en los jóvenes que en las jóvenes, lo cual no significa que a las mujeres no les gustara o no siguieran el reguetón; de hecho tenía muchas seguidoras, lo que se evidenciaba en los conciertos, pero por lo general no se identificaban con él de la misma manera que los del nivel cuatro, por ello se incluyeron en el nivel tres. La creación del género como producto musical fue pensada básicamente por hombres pero, a diferencia de otros géneros también creados por hombres, se elaboró bajo una postura más andrógena que universal, casi siempre en dirección a la seducción - con frecuencia machista- del sexo opuesto. Cuando las mujeres se incluyeron en este tipo de consumo musical, asumieron una postura que sirvió como complemento a la posición masculina; es decir, incorporaron referentes estéticos como cadenas gruesas, gorras, la gestualidad desafiante de los hombres o los modos de llevar el cabello, por sólo citar algunos ejemplos.

Oralidad secundaria: “-La caliente va pá arriba e’mí y yo pá arriba é la caliente”. La mayoría reconoció una fraseología típica del reguetón extendida a los discursos juveniles populares, pero la diferencia estribaba en la 
incorporación de estos discursos, por lo regular más tácita en la comunicación cotidiana. En este sentido, algunos argumentaron que el género bebía del sustrato popular de estereotipo marginal que le dio origen, por eso todavía poseía reminiscencias orales que aludían a este origen social.

¿Sobre qué tratan estas canciones? Algunos de sus significados atañen a "la calle, el barrio o el reparto" y a la cotidianeidad informal vivida por muchos de sus adeptos. Ahora bien, sobre este telón de fondo el cantante clama hacia el divertimento, "la fiesta o el party", el goce de lo femenino desde posturas lo mismo "románticas" que "groseras", la exhortación a poseer dinero, auto, mujeres. Así se viste el reguetón y así lo siguen muchos jóvenes que reconocen en éstas también sus pretensiones. Sin embargo, sería injusto, y a la vez fatalista, anquilosar en un discurso crítico el texto del reguetón con estas temáticas como sus únicos abordajes. También, en más de una ocasión, la comunidad de estereotipos marginales deja de ser telón de fondo y toma protagonismo, aludiendo entonces de manera crítica al acontecer cotidiano. Del mismo modo, también algunas canciones señalan otros temas universales e igualmente terminan inundando el gusto tanto como las otras.

No sería extraño que estos jóvenes consumidores del género, en el que ubicamos también a sus cantantes, fuesen sus cocreadores. Tras inspirarse en una parte del sustrato popular, los exponentes del reguetón hacen de esta experiencia un producto comercial, traducido en canciones que posteriormente se consumen de forma activa por una parte de la juventud, al sentirse copartícipes de esa filosofía "de la calle". De esta suerte se constituye su ciclo de reproducción sociocultural, en contraposición con la opinión crítica y prejuiciosa conformada en pruritos musicales, los cuáles ven en la extensión urbana del consumo de reguetón la causa fundamental "de la mala educación esgrimida por la juventud" y la pérdida de valores tradicionales. Con este ciclo que atañe solamente a lo textual se evidencia ciertamente que el reguetón no crea nada que no haya sido creado o reproducido en el habla cotidiana con anterioridad.
Eso sí, en espacios sostenidos por políticas culturales donde se le da cabida de manera indiscriminada se apoya su consiguiente legitimación.

\section{Conclusiones para una clasificación del consumo}

El consumo musical del reguetón por los jóvenes santiagueros es un hecho insoslayable, presente aun en quienes no les gusta el género; pero ello no se efectúa de manera homogénea sino a través de actitudes y prácticas de consumo que, colocando este producto musical como punto de partida, contribuyen de una manera u otra a la construcción de identidades musicales juveniles. El análisis clasificatorio apunta a una elevación de la tendencia del gusto y consumo del reguetón, al menos en la juventud santiaguera, pues mientras los que componen el primer eslabón clasificatorio son la minoría, el número se incrementa en los siguientes escaños del consumo musical.

Es preciso insistir en el carácter dinámico del reguetón, visible no sólo en el nivel musical, sino también en los procesos socioculturales que derivan de él, como el que sustenta la presente investigación. De ahí que a menudo los jóvenes, con el tiempo y de modo paulatino, transformen sus experiencias sociomusicales y se ubiquen en niveles diferentes. En este punto se impone observar la clasificación con una mirada crítica, con la finalidad de tener conciencia de sus posibles escollos empíricos. Constituye una operación conceptual de eslabones relativamente fijos, por lo cual a menudo no guarda plena correspondencia con las ciencias sociales en tanto que sus disímiles objetos de estudio son reiteradamente dinámicos.

Esta tendencia de comportamiento juvenil también está condicionada por el carácter flexible de las identidades, que se mantienen en constante construcción durante la vida entera (De la Torre, 2008), y por la expresión fluctuante del consumo cultural específicamente musical, cuyo desarrollo depende en gran medida de la labor creativa y de los procesos comerciales desarrollados desde los mercados musicales, tanto los legitimados tradicionalmente como los pequeños estudios emergentes. 


\section{Notas}

${ }^{1}$ Muchas frases empleadas en los subtítulos corresponden a fragmentos de textos muy comunes en canciones de reguetón o al título de las mismas. No tienen aquí un uso peyorativo.

2 Se conoce como AHS en Cuba a la Asociación de Hermanos Saíz, una institución cultural que agrupa y promociona a jóvenes talentos de disímiles manifestaciones del arte, así como a investigadores de las ciencias sociales y humanísticas. Sus espacios institucionales también funcionan para la recreación a través de la socialización juvenil que parte de la música, tanto en el marco de festividades que atañen a la ciudad, como inherente a su programación habitual.

${ }^{3}$ Este trabajo se realizó en el marco del Proyecto de Investigación "Consumos y prácticas culturales en jóvenes delorientecubano"llevadoacaboporelCentrodeEstudios para el Desarrollo Integral de la Cultura, en coordinación con algunas instituciones universitarias y culturales de la región oriental cubana. También constituye una parte de la tesis de maestría de su autora y se centró específicamente en la ciudad de Santiago de Cuba.

4 Esbozó a través de una ruta histórico-crítica los elementos teóricos alusivos al acto "colectivo" de consumir, agrupados en tres modelos: usos, formas y estrategias. La primera vertebra el consumo mismo, las restantes derivan de la primera y constituyen sus manifestaciones sociales.

5 En 1995, García Canclini aludía a cincos dimensiones socioculturales que explicaban la transmutación del sentido de ciudadanía avizorado al final del milenio. Una de ellas la expuso así: "La consiguiente redefinición del sentido de pertenencia e identidad, organizado cada vez menos por lealtades locales o nacionales y más por la participación en comunidades transnacionales o desterritorializadas de consumidores". Seguidamente proponía como ejemplo a los jóvenes en torno al rock, lo cual nos hace pensar en casos análogos como el que centra la presente temática, y en ese sentido ubicaba a los jóvenes que construían identidades en torno al reguetón, con lo cual también se sedimenta esta "ya no tan nueva" vivencia de ciudadanía.
${ }^{6}$ En estos estudios se recurre frecuentemente a un tratamiento de la identidad con una visión plural que subraya la multiplicidad de adscripciones definitorias de lo juvenil.

${ }^{7}$ La mismidad, absoluta igualdad o similitud, constituye una pauta de la identidad según los estudios psicológicos. Véase al respecto los trabajos de la psicóloga cubana Carolina de la Torre.

${ }^{8}$ Para la búsqueda de la información trabajamos con dos equipos de estudiantes jóvenes; uno conformado por estudiantes de la carrera de historia del arte y otro integrado por alumnos de las carreras de filosofía y sociología, quienes se insertaron conjuntamente con la autora del presente texto en varias comunidades urbanas santiagueras, donde destacan la universitaria, las comprendidas en el centro citadino y otras que pasan al imaginario social como periféricas.

9 Se explicitan en algunos tópicos, por ejemplo, la música misma y la estética, pero resultan epidérmicas porque no indican transformaciones profundas en la esencia del proceso analizado. Otras transformaciones expresadas en las variaciones preferenciales sobre el reguetón parecen más profundas, pero su explicación exigiría que se continuara con la investigación y que fueran incorporados nuevos asideros teóricos y metodológicos.

${ }^{10}$ Es necesario aclarar que cuando aludimos al "estilo" no nos referimos a su visión más global como "estilo de vida", la cual supondría otro análisis de esta realidad juvenil, que aunque no difiere de los resultados que aquí explicamos conduciría a otras aristas del análisis. De ese modo el consumo musical, aunque implícito, quedaría descentrado por el consumo en general. Existe un cordón umbilical que vincula ambas concepciones: estilo - como expresión de las culturas juveniles- y estilo de vida, pero en este material no pretendemos ahondar en tales relaciones sino concentrarnos en la primera.

${ }^{11}$ Se refiere al circuito que subyace tras las instituciones oficiales amparadas en políticas culturales sólidamente asentadas. Los discursos culturales del arte manifiestos de manera underground pueden ser tan o más visitados que los que pasan a formar parte de la "oficialidad". 
12 Rítmicamente, el reguetón sigue un patrón muy maleable que lo ha caracterizado desde sus inicios, amén de las múltiples transformaciones suscitadas en él a lo largo de su todavía corta existencia.

${ }^{13} \mathrm{Al}$ poseer una estructura rítmica flexible, se facilita el movimiento corporal y en consecuencia el baile. Se diferencia, por ejemplo, de la timba cubana o la salsa, las cuales requieren específicos pasos rítmicos. En el caso del reguetón, y en opinión de los jóvenes, cualquier manera de moverse al compás de su ritmo fuertemente percutido es válida. Cuando el baile se realiza en parejas se procede al típico baile del género llamado popularmente "perreo". Consiste en simular la copulación de los canes, de ahí que el hombre se coloca detrás de la mujer en posición erótica, mientras ambos mueven frenética pero rítmicamente las caderas.

${ }^{14}$ En el momento preciso de la recogida de datos, las frases más reconocidas fueron "a la my love" y "loco sexual" por encontrarse todavía a la moda las canciones de reguetoneros cubanos que las popularizaron.

${ }^{15}$ En ella pueden incluirse a la reguetonera puertorriqueña Martha Ivelisse Pesante, más conocida como Ivy Queen, La Diva, La Potra, La Caballota, o la cantante cubana más sobresaliente en este terreno, Patricia Blanco, más conocida como Patry White la dictadora.

${ }^{16}$ En este caso consiste en pantalones muy ceñidos y blusas anchas o no, exuberantes en colores intensos y adornos pintados.

${ }^{17}$ El Yonki fue el nombre con el que saltó a la fama, al menos nacionalmente, el reguetonero cubano Alejandro Santoya Lorensín. Su estética popularizó un modo de llevar el cabello muy parecido a lo punk: la cabeza rapada o semirrapada y los cabellos del centro en posición vertical.

${ }^{18}$ Es común entre los cantantes de reguetón, cuando llegan a consolidarse en el gusto popular, la exhibición de estéticas más inaccesibles en término económicos; por ejemplo, si antes usaban pulóveres apretados, luego usan chaquetas de vestir. Por ello, la asunción de la estética por parte de los jóvenes no se ubica necesariamente en el uso objetivo de la misma, sino que comienza con la pretensión de su uso, dado que son muy pocos los que poseen el caudal económico necesario para vestirse como sus cantantes favoritos cuando éstos ya son populares. Por otro lado, como el joven no puede usar trajes, gruesas cadenas doradas o gorras de marca, escoge prendas más accesibles, como los pulóveres de colores vivos — que todavía caracterizan a más de un cantante de reguetón-, las gorras de precios más bajos y los lentes oscuros.

\section{Referencias bibliográficas}

Bermúdez, Emilia, (2008) "Roqueros y roqueras, pavitos y pavitas, skaters, lesbianas y gays. El papel del consumo cultural en la construcción de representaciones de identidades juveniles (El caso de algunos jóvenes que van a los malls de Maracaibo en Venezuela)" en Revista Latinoamericana de Ciencias Sociales, Niñezy Juventud. Juliodiciembre, vol. 6, núm. 2, pp. 615-666.

Bourdieu, Pierre, (1979) La distinción. Criteriosy bases sociales del gusto. Madrid, Taurus.

Callejo, Javier, (1995a) "Elementos para una teoría sociológica del consumo” en Revista Paper. Núm. 47, pp.75-96.

Callejo, Javier, (1995b) "La construcción del consumidor global” en Revista Sistema. Núm. 126, pp.77-96.

Casanella, Liliana, Neris González y Grizel Hernández, (2005) "El reguetón en Cuba, un análisis de sus peculiaridades" en VII Congreso IASPM-AL, La Habana. Disponible en: www.casa.cult.cu/musica/iaspm/ resumenes.doc [consultado 10 de diciembre de 2009].

De Certeau, Michel, (1996) La invención de lo cotidiano. Artes de hacer. México, Universidad Iberoamericana.

De la Torre Molina, Carolina, (2008) Las identidades: una mirada desde la psicología. La Habana, Instituto Cubano de Investigación Cultural Juan Marinello.

Feixa, Carles, (1999) De jóvenes, bandas y tribus. Antropología de la juventud. Barcelona, Ariel.

García Canclini, Néstor, (1995) Consumidores y ciudadanos. Conflictos multiculturales de la globalización. México, Grijalbo.

García Canclini, Néstor, (2006) "El consumo cultural. Una propuesta teórica” en Guillermo Sunkel (coord), 
El consumo cultural en América Latina. Colombia, Convenio Andrés Bello, pp. 72-95.

Guzmán Cárdenas, Carlos E., (2008) “Las nuevas síntesis urbanas de una ciudadanía cultural. (La ciudad como objeto de consumo cultural" en Observatorio Cultural y Comunicacional de Venezuela. Disponible en: www. scribd.com [consultado el 7 de enero del 2011].

Marcial, Rogelio, (2009) "Voces de la diversidad. Culturas juveniles: referentes simbólicos y espacios de interpelación" conferencia dictada en la Xl Reunión Nacional y IV Encuentro Internacional de Investigadores sobre Juventud. La Habana, Centro de Estudios de la Juventud.

Marinas, José Miguel, (2000) "Simmel y la cultura del consumo" en Revista Española de Investigaciones Sociológicas Reis. Núm. 89, pp. 184-118.

Marx, Karl, (1981) El capital. La Habana, Ciencias Sociales. Monsonyi, Esteban, (1990) "La oralidad" en Revista Oralidad de la UNESCO. Núm.2, pp.5-19.

Pallarés, Joan, Carmen Costa y Carles Feixa, (2002) "Okupas, makineros, skinheads. Ciudadanía y microculturas juveniles en Cataluña” en Feixa, Carles, Carmen Costa y Joan Pallarés (coords.), Movimientos juveniles en la península Ibérica. Graffitis, grifotas, okupas. Barcelona, Ariel, pp. 89-113.

Silbermann, Alphons, (1961) Estructura social de la música. Madrid, Taurus.

Sunkel, Guillermo, (2006) "El consumoen la investigación comunicación-cultura en América Latina" en Sunkel, Guillermo (coord.), El consumo cultural en América Latina. Colombia, Convenio Andrés Bello, pp.15-4l.

Urteaga Castro Pozo, Maritza, (1998) Por los territorios del rock. Identidades juveniles y rock mexicano. México, Centro de Investigación y Estudios sobre Juventud/ Dirección General de culturas Populares.

Ziquero, Raquel, (2006) "El indiscreto encanto del reguetón. A propósito de una explosión en el campo cultural latino" en Revista Movimiento de la Agencia Cubana del Rap. Núm. 6, pp.16-17.

Zurbano, Roberto, (2006) "Mami no quiero más reggaetón" en Revista Movimiento de la Agencia Cubana del Rap. Núm. 6, pp.4-12. 